\title{
Panduan Rancang Kota: Konsep Perancangan Koridor Ryacudu, Kota Bandarlampung
}

\author{
Fran Sinatra1 ${ }^{1}$ David Ricardo², Elisabet Nungki Septania², Eduwin Eko Franjaya ${ }^{3}$ \\ (1) Program Studi Perencanaan Wilayah dan Kota, ITERA. (fran.sinatra@pwk.itera.ac.id) \\ (2) Program Studi Arsitektur, ITERA. \\ (3) Program Studi Arsitektur Lanskap, ITERA.
}

\begin{abstract}
Abstrak
Bandar lampung merupakan salah satu Kota Metropolitan yang ada di Sumatera di Bangian Selatan. Tingginya tingkat urbanisasi dan pembangunan infrastruktur skala nasional berdampak pada pertumbuhan kota ini. Kawasan Koridor Ryacudu sangat dipengaruhi perkembangannya oleh pembangunan infrastruktur skala nasional seperti pembangunan Jalan Toll Trans Sumatera (JTTS) dan kawasasan Terpadu pendidikan LARALIN (UNILA, ITERA, UINRIL). Saat ini, koridor Ryacudu belum begitu optimal dalam melayani pergerakan. Disisi lain, tingginya tingkat heterogenitas Kota Bandar Lampung menyebabkan terkikisnya karakter buaya lokal yang ada. Penelitian ini bertujuan untuk menyususn panduan rancangan kawasan Koridor Ryacudu untuk meningkatkan pelayanan koridor dan meningkatkan karater atau citra kawasan dengan mengangkat identitas etnik Lampung. Metode rancang yang digunakan adalah metode desain terfaragmen (Fragmental Design Method). Dalam upaya mencapai kualitas rancangan kawasan yang diinginkan maka ada beberapa komponen rancang kota yang harus disusun panduan rancangannya yang meliputi: panduan rencana struktur ruang, peruntukan lahan dan intensitas lahan, tata bangunan, sistem pergerakan dan sirkulasi, dan tata hijau dan ruang terbuka publik.
\end{abstract}

Kata kunci : Citra kawasan, panduan rancang kota, pembangunan berkelanjutan

\begin{abstract}
Bandarlampung is a metropolitan area in Southern Sumatera. The vast number of urbanization and rapid development of infrastructures such as JTTS and Integrated Higher Education District LARALIN (UNILA, ITERA, UINRIL) affect this area, Ryacudu Corridor. To date, this corridor has not yet optimum in the level of services. Moreover, the high number of heterogeneity of the ethnic of Bandarlampung leads to degradation of local identity as a part of the city image. This paper aims to arrange the urban design guideline of Ryacudu Corridor, to encourage the level of service of Ryacudu Corridor and adopt the local identity of Lampung, Piil Pesenggiri, as corridor image toward sustainable development. The fragmental design method is employed in this study. In order to achieve the optimum place quality in the future, thus there are several urban design components should be designed, which are a guideline of site structure plan, land use and intensity, bulk and massing, circulation system, and public open space.
\end{abstract}

Key word: Image of place, urban design guidelines, sustainable development.

\section{Pengantar}

Kota Bandarlampung merupakan salah satu kota metropolitan yang ada di Sumatera Bagian Selatan. Jumlah penduduk Kota Bandar Lampung tahun 2019 sebeesar 1.051 .500 jiwa yang terdiri dari 20 kecamatan dan 126 kelurahan (BPS, 2020). Kawasan metropolitan sejatinya merupakan kawasan perkotaan yang berdiri sendiri atau kawasan perkotaan inti dengan kawasan di sekitarnya yang saling memiliki keterkaitan dan dihubungkan dengan sistem jaringan prasarana wilayah yang terintegrasi dengan jumlah penduduk sekurang-kurangnya 1 juta jiwa (UU No. 26/2007).

Permasalahan yang kini sedang dan akan dihadapi di Kota-kota pada umumnya adalah tingginya jumah penduduk yang tinggal dikawasan perkotaan akibat proses urbanisasi, proses pengkotaan secara alamin maupun migrasi (UNDP, 2016). Persoalan yang sering muncul adalah kota berkembang 
ke arah yang tidak berkelanjutan dan hilangnya identitas lokal. Pembangunan berkelanjutan berkaitan dengan tiga dimensi: dimensi lingkungan, dimensi sosial, dan dimensi ekonomi (Shah, 2008).

Dimensi lingkungan berkaitan bagaimana kota dapat mengantisipasi kemacetan, ketersedian infrastruktur yang ramah lingkungan (Shah, 2008; Klarin, 2018). Dimensi sosial salah satunya berkaitan dengan bagaimana identitas lokal masyarakat dapat dipertahankan dan diaktualisasikan kedalam citra kawasan (Dril dkk, 2016). Sedangkan dimensi ekonomi berkaitan bagaimana kawasan budidaya yang ada dapat terbangun dengan mengoptimalkan pembangunan untuk kesejahteraan publik dan inklusif (Shah, 2008).

Kota Bandarlampung sebagai kota transit yang menghubungkan pergerakan anatara kota-kota di Sumatera dengan kota-kota di Pulau Jawa sangat berdampak pada pertumbuhan kota. Saat ini, mulai terhubungnya pergerakan melalui pembangunan ruas JTTS yang menghubungkan Kota Palembang Bandarlampung - pelabuhan Bakauheni berdampak pada pertumbuhan kawasan perkotaan.

Koridor Ryacudu merupakan salah satu kawasan yang pertumbuhannya cukup pesat hal ini disebabkan oleh beberapa faktor seperti: Koridor ini menjadi gerbang pintu toll menghubungkan Kota Bandar Lampung dengan Kota-kota lainnya. Sealin itu, di sekitar koridor Ryacudu tumbuh kegiatan baru yang merupakan bagian dari dinamika pembangunan eksternal seperti pendirian Kampus Keteknikan skala nasional, Institut Teknologi Sumatera, yang merupakan bagian dari kebijakan nasional. Koridor ini juga menghubungkan kegiatan pemerintahan, Provinsi Lampung di Kota baru, dengan pusat perdagangan dan jasa di Tanjung Karang. Sebagai kawasan yang terdampak akibat pembangunan infrastruktur, JTTS, dan Kawasan Pendidikan Terpadu (KPT) LARALIN (UNILA-ITERA-IAIN), Koridor Ryacudu harus dikembangkan ke arah kawasan yang berkelanjutan dan dengan menciptakan citra kawasan yang dapat menggambarkan nilai budaya Lampung sebagai jati diri kawasan.
Panduan Rancang Kota merupakan salah satu perangkat perencanaan dan pengendali pertumbuhan kawasan serta memberi panduan terhadap wujud bangunan dan lingkungan pada suatu kawasan (Permen PU No. 06/PRT/M/20017). Dengan panduan ini akan memberikan arahan terhadap wujud pemanfaatan lahan, ragam, arsitektural dari bangunan-bangunan sebagai hasil rencana teknis/rancang bangunan (building design), terutama pada kawasan/daerah tertentu yang memiliki karakter khas (Shirvani, 1985; Lang, 1994; Cliff, 1999; Permen PU No. 06/PRT/M/20017). Atas dasar persoalan tersebut maka tujuan dari artikel ini adalah menyusun panduan rancang kawasan Koridor Ryacudu sebagai bagian dari sistem pergerakan dan jaringan kawasan dengan menciptakan citra kawasan berbasiskan budaya Lampung.

\section{Metodologi}

Desain penelitian yang digunakan adalah metode desain terfragmen (Fragmental Method). Metode ini merupakan bentuk lain dari metode desain komprehensif rasional (metode sinopsis) namun dalam bentuk lebih singkat (Shirvani, 1985). Penelitian ini menggunakan empat tahapan: 1. Tahap Pengumpulan data primer dan data sekunder, 2. Analisis data, 3. Formulasi visi dan prinsip perancangan kawasan, dan 4. Penyusunan panduan rancangan kawasan.

Tahap Pertama. Pada tahap ini dilakukan pengumpulan data baik data primer maupun data sekunder. Kualitas data yang dihasilkan sangat berkaitan erat bagaimana data tersebut diperoleh dan sumbernya (Yunus, 2010). Ada dua jenis data yang digunakan, meliputi: data primer dan data sekunder. Data primer adalah data yang dihasilkan dari hasil observasi dan interview. Data observasi berkaitan dengan pengamatan kondisi eksisting kawasan rancangan yang meliputi gunalahan dan kegiatan eksisting, sistem pergerakan, dan sistem jaringan jalan. Interview dilakukan kepada pengguna jalan dari berbagai stakeholder seperti pemerintah, dan masyarakat. Interview menghasilkan data terkait preperensi pemangku kepentingan terhadap citra kawasan yang diinginkan dan arahan pengembangannya. Data sekunder yang dikumpulkan berkaitan dengan data nilai dan identitas kebudayaan etnis lampung, fallsafah hidup dan kearifan lokal lainnya. 
Selain itu, data sekunder yang dikumpulkan juga berkaitan dengan dokumen rencana tataruang skala makro (Rencana Tata Ruang Wialyah Kota bandar lampung, Kab. Lampung Selatan dan Provinsi Lampung) dan kebijakan pembangunan.

Tahap kedua. Pada tahapan ini dilakukan analisis dari data yang telah dikumpulkan baik data primer maupun data sekunder. Teknik analisis yang digunakan adalah analisis deskriptif kuantitatif dan kualitatif. Deskriptif kuantitatif digunakan melalui analis spasial dan data statistik berkaitan dengan luas guna lahan, sistem pergerakan, dan jaringan jalan. Sedangkan analisis deskriptif kualitatif dengan menggunakan teknik analisis konten/isi untuk mengintepretasikan persepsi para pemangku kepentingan terhadap budaya lokal yang dapat diadopsi pada rancangan dan arahan kebijakan tataruang yang ada saat ini dan dimasa yang akan datang.

Tahap ketiga. Setelah data dan informasi dianalisis, kegiatan yang dilakukan selanjutnya berupa penyusunan visi dan prinsip perancangan Kawasan Koridor Ryacudu. Visi dan prinsip ini merupak konsep atau gambaran kualitas rancangan yang akan dicapai pada masa yang akan datang dalam bentuk gambar konsep dan statement rancangan, arahan pembangunan secara normatif.

Tahap keempat. Penyususnan panduan rancangan dari setiap komponen rancang kota, seperti Struktur ruang, arahan guna lahan dan intensitas lahan, tata bangunan, sistem pergerakan, dan sistem ruang terbuka.

\section{Karakteristik Koridor Ryacudu}

Kawasan rancangan terletak di Kawasan Perbatasan anatara Kota Bandar Lampung (Kecamatan Sukarame) dan Kab. Lampung Selatan (Kecamatan Jati Agung). Panjang koridor yang dirancang sepanjang $6.5 \mathrm{Km}$ mulai dari gerbang Toll ITERA KOTA BARU (Gerbang Toll menuju Kota Bandar Lampung) sampai pada By Pass Soekarno-Hatta. Luas dari kawasan rencana berkisar 127,04 Ha. Pada penelitian ini, Koridor Ryiacudu dibagi kedalam 6 (enam) segmen pengembangan. Pembagian segmen ini didasarkan pada batas fisik dan kawasan fungsional yang ada. Segmen I merupakan segemen Gerbang Toll ITERA Kota Baru, dengan panjang 800M.

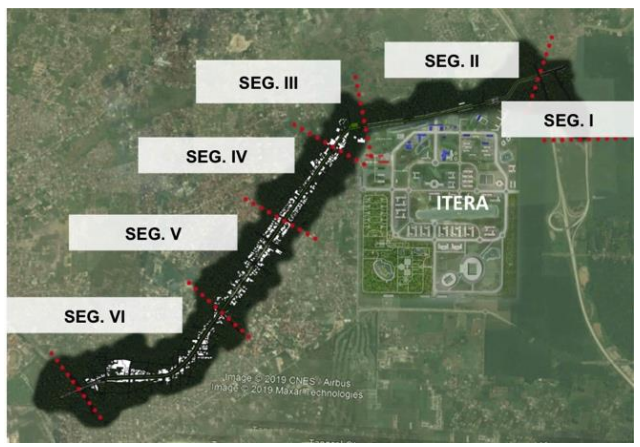

Gambar 1 Lokasi Penelitian

Segmen II ITERA, meliputi jalan Terusan Ryacudu yang secara fungsional merupakan kawasan pendidikan tinggi (ITERA). Segmen III Mesjid Ariran Raya yang merupakan kawasan perbatasan antara Kota Bandar Lampung dan kabupaten Lampung Selatan dengan panjang sekita $2 \mathrm{Km}$. Segemen IV, Segmen KORPRI, merupakan segemen yang didominasi oleh kawasan hunian dengan pajang segemen sekitar $416 \mathrm{M}$, Segmen V, Pasar KORPRI, dengan panjang kawasan rancangan mencapai $980 \mathrm{~m}$. Dan Segmen VI, Way Dadi, Panjang segmen ini mencapai 1,4 Km. Gambar 1 menunjukkan lokasi Kawasan Rancangan dan Pembangian Segmen.

Lokasi perencanaan koridor pada kondisi eksisting memiliki dominan penggunaan lahan permukiman dengan beberapa bagian di koridor perencanaan terdapat gunalahan perdagangan dan jasa, Ruang Terbuka Hijau (RTH), kawasan pertanian dan lainnya (gambar 2). Dimana koridor perencanaan menghubungkan dengan beberapa kegiatan prasarana umum seperti perguruan tinggi ITERA dan UIN RIL. Jalan Ryacudu pada koridor perencanaan sendiri memiliki status jalan Arteri Sekunder yang menjadi pintu masuk Kota Bandar Lampung melalui jalan Terusan Ryacudu dari arah Kota Baru. 


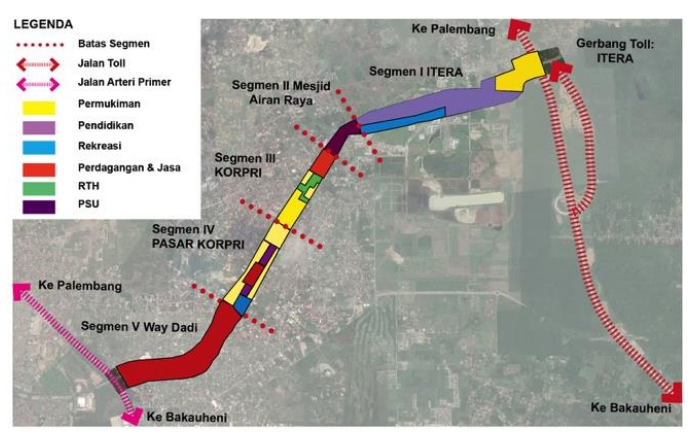

Gambar 2 Peta Guna Lahan Makro disekitar Koridor Ryacudu, Kecamatan Sukarame

Koridor Ryacudu dalam pengembanganya akan sangat berperan dalam perubahan pembangunan kawasan pendidikan Terpadu ITERA dan UIN RIL. Hal ini akan berpengaruh signifikan terhadap pertumbuhan kawasan baru dalam memenuhi kebutuh di kawasan pendidikan. Maka dari itu peran perencanaan pengembangan Koridor Ryacudu guna mempersiapkan pertumbuhan kawasan yang teratur serta memiliki semangat visi memperkenalkan corak budaya Lampung melalui desain-desain yang diterapkan pada kawasan tersebut serta mengadopsi teknologi cerdas. Dari kondisi eksisting, kawasan Koridor Ryacudu berpotensi untuk dikembangkan sebagai kawasan gunalaha campuran anatara kawasan hunian, pendidikan tinggi, perdagangan dan jasa skala lokal, dan perkantoran.

Gambar 3 menggambarkan koridor perencanaan Berada dikawasan strategis pendidikan tinggi, sehingga berpotensi untuk pengembangan kawasan permukiman dan perdagangan dan jasa. Namun ada hal yang perlu diperhatikan pada kawasan strategis pendidikan tinggi, masih belum adanya instrumen pengendalian pemanfaatan ruang yang baik, sehingga berpotensi pada pembangunan yang tidak terencana, sehingga kawasan berpotensi tumbuh secara sprawl mengikut kebutuhan ruang.

Pengaruh adanya JTTS di sekitar pintu TOLL sangat berdampak pasca toll sudah beroperasi. Koridor perencanaan, Jalan Ryacudu dan Terusan Ryacudu, menjadi jalan utama menuju Kota Bandar Lampung, secara langsung akan menumbuhkan kegiatan kawasan pada sekitarnya terutama pada jaringan jalan di Ryacudu.

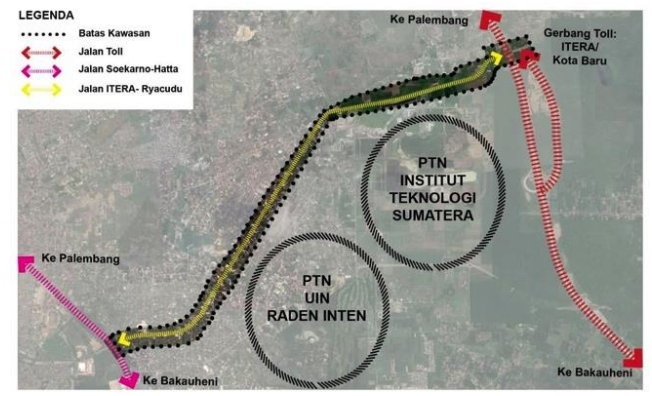

Gambar 3 Sebaran Kegiatan dan Jaringan Jalan di Sekitar Koridor Ryacudu

Kawasan koridor yang tepat berada pada kawasan yang dilalui oleh sistem pergerakan yang strategis seperti Gerbang Toll, Rencana Terminal Tipe B, dan Rencana Stasiun LRT berpotensi dapat membantu meningkatkan akitivitas sirkulasi kegiatan pada kawasan tersebut. Kawasan ini juga berpotensi dapat berkembang pesat karena sebagai pintu masuk Kota Bandar lampung dan didukung dengan kegiatan eksisting seperti perguruan tinggi dan kawasan perdagangan dan jasa di sekitar koridor Jl. Ryacudu.

Namun Koridor Ryacudu belum dapat mendukung sistem pergerakan kendaraan yang optimum, baik dari segi kapasitas maupun kualitas Sehingga perlu mengintegrasikan BRT dengan Rencana Stasiun LRT yang akan dibangun. Dalam upaya untuk meningkatkan kualitas dan layanan jaringan jalan koridor Ryacudu, diperlukan pengintegrasian kawasan koridor dengan terminal dan rencana stasiun LRT serta di lakukannya pembuatan jalur cepat dan lambat pada jalan utama Koridor Ryacudu. Ditambahkannya rencana sistem transportasi publik ini juga berkaitan dengan distribusi guna lahan yang akan dikembangkan seperti Kawasan Permukiman, Perdagangan dan Jasa Sekala Sub Pusat Kota, dengan cara memaksimalkan mix land use.

\section{Visi dan Misi Rancangan Koridor Ryacudu \\ Kawasan Koridor Jalan Ryacudu memiliki permasalahan dan potensi untuk dikembangakan. Visi yang disusun berusaha untuk meminimalkan permaslahan yang ada dengan memaksimalkan potensi. Sebagai bagian dari upaya penataan fungsi dan fisik}


kawasan, sesuai dengan kebutuhan dan kondisi lokal yang memperhatikan keserasian dengan alam dan budaya sekitarnya sehingga visi perancangan Kawasan Koridor Ryacudu sebagai "Smart growth Corridor based on Lampung Indentity" yang memiliki tujuan untuk: 1. Smart growth, pembangunan kawasan terbangun dimasa yang akan datang dengan tata kelola dan terencana dengan baik dengan menghindari pembangunan yang tidak diinginkan; 2. Smart Corridor dimaksudkan sebagai jaringan pergerakan yang dapat mendukung kegiatan dan guna lahan baik saat ini maupun dimasa yang akan datang berbasis pada teknologi; dan 3. Local identity "Piil Pesenggiri" ditujukan untuk menciptakan karakter kawasan yang mengangkat budaya Lampung dengan gubahan modern sebagai citra kawasan, Jalan Ryacudu menjadi jalinan cerita pilosofi dan filsafah hidup masyarakat Lampung yang menjaga kehormatan, ramah tamah, menghargai keanekaragaman, dan bergotoroyong.

Untuk mewujudkan karakter yang ingin dicapai tersebut diperlukan penyusunan misi pengembangan kawasan yang diturunkan dari visi pengembangnya, dimana pada akhirnya dapat menjadi acuan dalam pengembangan Kawasan Koridor Ryacudu. Adapun misi pengembangan kawasan meliputi:

1. Mengoptimalkan pelayanan Koridor Ryacudu dalam mendukung sistem pergerakan pada skala regional; 2 . Mengintegrasikan sistem pergerakan kendaraan dengan transportasi publik; 3 . Menerapkan pembangunan kawasan kompak dan mixed use; 4. Menyediakan jalur pedestrian, dan jalur jalan yang ramah dan nyaman; dan 5. Menciptkan karakter kawasan mengangkat filsafah hidup mansyarakat Lampung "Piil Pesenggiri" dengan gubahan arsitektur modern.

\section{Panduan Rencana Rancangan Koridor Ryacudu}

Panduan rencana umum menjadi pedoman arahan pembangunan secara keseluruhan yang meliputi komponen perancangan kawasan seperti: 1. Panduan rencana struktur ruang; 2. Panduan Rencana Penggunaan Lahan dan Intensitas Lahan; 3. Tata bangunan, 4. Panduan sistem pergerakan; dan 5. Sistem Ruang Terbuka (Shirvani, 1985; \& Permen PU No. 06/PRT/M/20017).

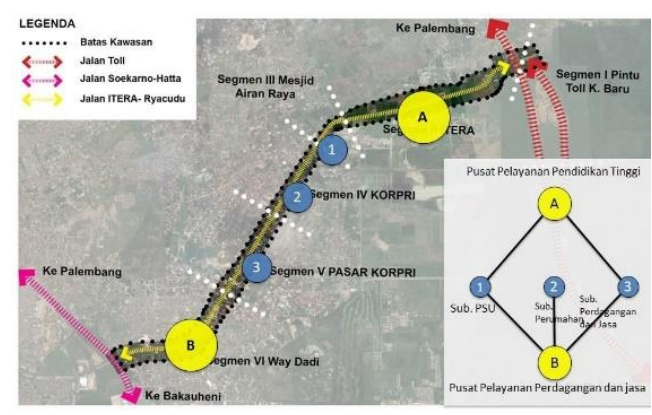

Gambar 4 Peta Rencana Struktur Ruang

Koridor Ryacudu

Rencana struktur ruang Kawasan merupakan kerangka tata ruang wilayah yang tersusun atas sebaran pusat layanan yang berhierarki satu sama lain yang dihubungkan oleh sistem jaringan prasarana, sarana, utilitas. Terdapat dua hirarki struktur yang direncanakan, meliputi: pusat dan sub-pusat. Ada dua pusat yang direncanakan yaitu pada segemen II Kampus ITERA dan Segmen VI Segemen Way Dadi. Pusat pada Segemen I diarahkan untuk pelayanan kegiatan pendidikan tinggi sedangkan pusat di Segmen VI Way Dadi diarahkan untuk pelayanan perdagangan dan jasa skala lokal. Sedangkan segmen lainnya, meliputi Segemen I, III, IV, dan $\mathrm{V}$ direncanakan menjadi subpusat yang hanya melayani area disekitar segmen masing-masing. Gambar 4 menunjukan rencana struktur ruang di Kawasan Koridor Ryacudu.

Rencana penggunaan lahan merupakan bentuk dari pemanfaatan lahan yang berkaitan dengan pengaturan komponen rancangan yang berperan penting dalam alokasi penggunaan dan penguasaan lahan/tata guna serta sistem jaringan yang akan ditetapkan. Komponen penataan penggunaan lahan meliputi peruntukan lahan makro yang mengikuti rencana tata ruang yang ada, dan peruntukan lahan mikro yang ditetapkan berdasarkan pada skala yang lebih detail. Secara keseluruhan peruntukan lahan yang direncanakan meliputi: Perdagangan dan Jasa, Sarana Pelayanan Umum (SPU), Ruang Terbuka Hijau (RTH) Hunian, dan Pendidikan Tinggi. 


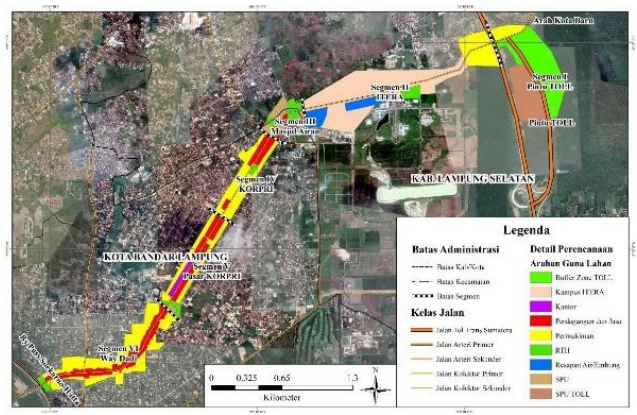

Gambar 5 Rencan Peruntukan Lahan Mikro Kawasan Koridor Ryacudu

Sedangkan intensitas pemanfaatan lahan berkaitan dengan ketentuan mengenai besaran pembangunan yang diperbolehkan pada suatu blok atau zona pada setiap segemen yang berkaitan dengan pengaturan Kofisen Dasar Bangunan (KDB) maksimum, dan Kofisien Lantai Bangunan (KLB) Maksimum. Penetapan intensitas pemanfaatan lahan yang direncanakan akan mengikuti struktur ruang dan blok atau zona yang direncanakan (Tabel 2.2).

Panduan Tata bangunan berkaitan dengan pengaturan ketinggian bangunan, citra atau karakter fisik lingkungan. Ketinggian bangunan akan merujuk pada intensitas lahan yang direncanakan, baik KDB maupun KLB. karater bangunan dan lingkungandiwujudkan melalui penataan tema-tema desain yang berkaitan dengan falsafah hidup masyarakat lampung "Piil Pesenggiri" yang dibagi kedalam enam segemen. Adapun nilai falsafah tersebut akan diterapkan di enam segmen kawasan rencana, Segmen I tema yang diangkat berupa Juluk Adok, Segmen III Nemui-Nyimah, Segmen IV Tittie-Gumattie, Segmen V Ngah Nyampur, dan Segmen VI Sakai Sambian (Tabel 2.1).

Tabel 2.1 Penerapan Nilai Piil Pesenggiri pada Segmen Rencana

\begin{tabular}{lll}
\hline Seg. & $\begin{array}{l}\text { Falsafah } \\
\text { Hidup "Piil- } \\
\text { Pesenggiri" }\end{array}$ & \multicolumn{1}{c}{ Makna } \\
\hline I \& II & Juluk-Adok & $\begin{array}{l}\text { Gelar adat, menjaga nama } \\
\text { baik dalam kehibupan } \\
\text { bermasyarakat }\end{array}$ \\
\hline \multirow{2}{*}{ III } & Nemui & $\begin{array}{l}\text { Suka bersilaturahmi, ramah } \\
\text { dan santun terhadap tamu } \\
\text { dan kaum kerabat dan } \\
\text { memiliki rasa setia kawan }\end{array}$ \\
\hline
\end{tabular}

\begin{tabular}{lll}
\hline Seg. & $\begin{array}{l}\text { Falsafah } \\
\text { Hidup "Piil- } \\
\text { Pesenggiri" }\end{array}$ & \multicolumn{1}{c}{ Makna } \\
\hline IV & $\begin{array}{l}\text { Tittie- } \\
\text { Gumattie }\end{array}$ & $\begin{array}{l}\text { Bersikap sopan santun dan } \\
\text { mengutamakan kebaikan }\end{array}$ \\
\hline V & $\begin{array}{l}\text { Nengah } \\
\text { Nyampur }\end{array}$ & $\begin{array}{l}\text { Bersosialisasi, } \\
\text { bermusyawarah dan penuh } \\
\text { rasa tanggung jawab }\end{array}$ \\
\hline \multirow{2}{*}{ VI } & $\begin{array}{l}\text { Sakai } \\
\text { Sambian }\end{array}$ & $\begin{array}{l}\text { Saling Tolong menolong, } \\
\text { Bergotoroyong, dan saling } \\
\text { menghargai }\end{array}$ \\
\hline Sumber: Hasil Analisis, 2020
\end{tabular}

Segemen I (Gerbang Toll) dan II (ITERA) tema Juluk-Adek (prinsip keberhasilan) dapat bermakna memiliki gelar dan nama besar untuk mendapatkan gelar atau keberhasilan hendaknya setiap individu dalam tatanan masyarakat Lampung rela berkorban (Sinaga, 2012; Nurrohman, 2017). Dalam penerapannya, Juluk-Adek diintepretasikan kawasan pendidikan Tinggi, Institut Teknologi Sumatera, demi mendapatkan kehormatan dan gelar harus berkorban dan bersungguhsungguh. Perancangan pada segmen ini diarahkan pada tatanan lanskap bernuansa pendidikan dan perjuangan untuk mendaptkan gelar pendidikan yang lebih tinggi (gambar 6).

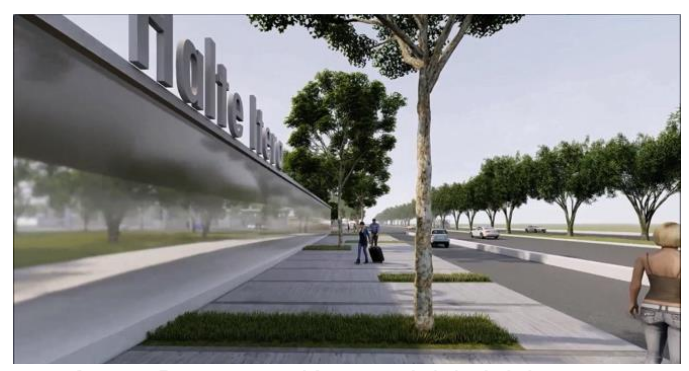

Gambar 6 Penerapan Konsep Juluk-Adek (keberhasilan) di Segmen I\&II

penghargaan ini berupa sikap menghormati dan ramah kepada orang lain (Sinaga, 2012; Nurrohman, 2017). Segmen ini merupakan kawasan Perbatasan yang menjadi gerbang ke Kota Bandar Lampung setelah keluar dari Pintu Tol ITERA Kota Baru. Implementasi desain pada segmen ini diintepretasikan pada penyediaan gerbang selamat datang di Kota bandar Lampung dengan sentuhan desain dan warna yang hangat dan ramah (gambar 7). 


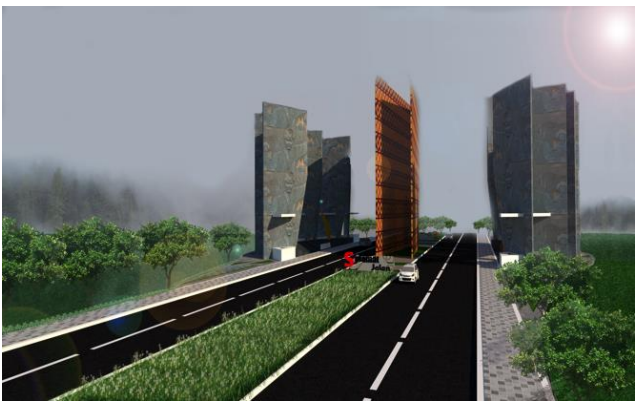

Gambar 7 Penerapan Nilai Nemui-nyimah di Segmen III

Segemen IV (KORPRI) Tittie-Gumattie berarti memiliki kebiasaan dan sikap yang baik (Pranoto dan Wibowo, 2018). Implementasi Tittie-Gumattie pada konsep desain segmen ini melalui penyediaan ruang publik yang mengarahkan pada pengguna koridor yang menekankan pada moral dan sikap terpuji. Pada segmen ini penggunaan lahan didominasi sebagai lingkungan hunian baik masyarakat lokal maupun tempat tinggal mahasiswa ITERA dan UIN Raden Inten Lampung (gambar 8).

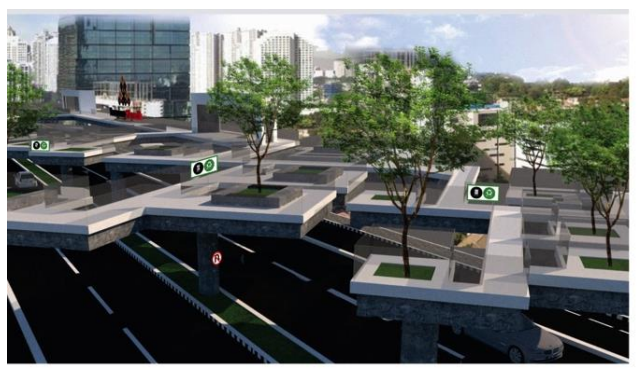

Gambar 8 Penerapan Titie-Gumatie di Segmen IV

Segemen V (Pasar KORPRI) Ngah-Nyampur (prinsip persamaan dan toleransi) bermakna sikap teleransi yang tinggi dan memiliki rasa kekeluargaan (Pranoto dan Wibowo, 2018). Prinsip ini dimplementasikan melalui penyediaan ruang terbuka publik berupa sky walk yang menjadi wadah ruang berinteraksi masyarakat dengan menekankan pada inklusifitas sebagai bagian tatanan kehidupan manusia.

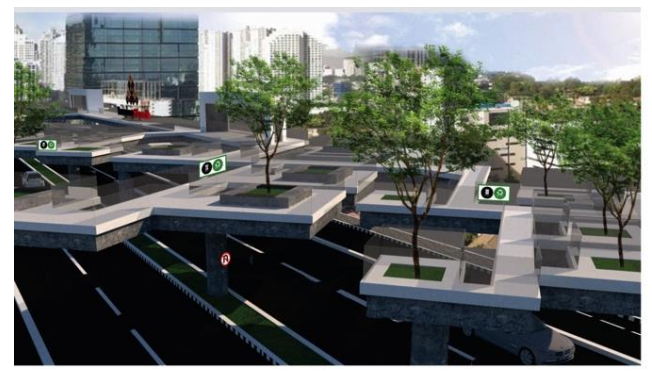

Gambar 9 Penerapan Ngah-Nyampur di Segmen V

Segemen VI (Way Dadi) Sakai Sabian (prinsip kerjasama) dimaknai sebagai sebuah sikap orang lampung yang saling bergotoroyong, solidaritas, dan tolong menolong (Pranoto dan Wibowo, 2018; Nurrohman, 2017). Implementasi nilai sakai sabian dalam rancangan di segmen ini menekankan pada kehidupan yang selaras dan bekerjasama baik secara ekonomi maupun sebagai umat manusia. Gotoroyong dalam bidang ekonomi diimplementasikan dengan pengembangan kawasan perdagangan yang bertujuan untuk meningkatkan kesejahteraan bersama dan penyediaan taman publik yang inklusif berbagai usia berupa taman kreatif untuk kalangan muda dan taman lansia (gambar 10).

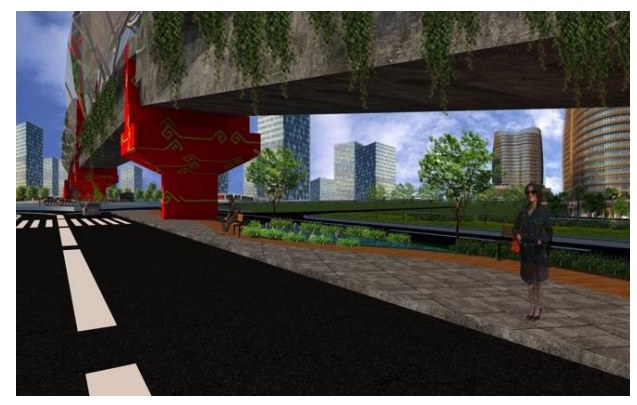

Gambar 10 Penerapan Sakai Sabian di Segmen VI

Penghubung berkaitan dengan pengaturan jaringan jalan dan pergerakan, sirkulasi ke ndaraan umum, sistem parkir, sirkulasi kendaraan non-motor seperti sepeda dan sirkulasi pejalan kaki Jaringan jalan mengikuti dari arahan rencana tata ruang dan wilayah (RTRW) Kota Bandar Lampung, dimana hirarki jalan Ryacudu dan Terusan Ryacudu merupakan jalan arteri sekunder. 
Tabel 2. Panduan Rancangan

\begin{tabular}{|c|c|c|c|c|c|c|}
\hline \multirow{2}{*}{ Komponen } & \multicolumn{6}{|c|}{ Panduan Rancangan } \\
\hline & Seg. I & Seg. II & Seg. III & Seg. IV & Seg. V & Seg. VI \\
\hline Struktur Ruang & $\begin{array}{l}\text { Sub } \\
\text { Pusat }\end{array}$ & Pusat I & Sub Pusat & Sub Pusat & Sub Pusat & Pusat II \\
\hline Guna Lahan & $\begin{array}{l}\text { RTH; } \\
\text { Hunian; } \\
\text { SPU } \\
\text { Toll }\end{array}$ & $\begin{array}{l}\text { Hunian; } \\
\text { RTH; } \\
\text { Pendidika } \\
\text { n }\end{array}$ & $\begin{array}{l}\text { Perdaganga } \\
\text { n; SPU; } \\
\text { RTH }\end{array}$ & $\begin{array}{l}\text { Perdagangan } \\
\text { dan Jasa; } \\
\text { RTH; Hunian }\end{array}$ & $\begin{array}{l}\text { SPU; RTH; } \\
\text { Perdagangan } \\
\text { dan Jasa; } \\
\text { Hunian }\end{array}$ & $\begin{array}{l}\text { Perdagangan } \\
\text { dan Jasa; RTH; } \\
\text { Hunian }\end{array}$ \\
\hline \multicolumn{7}{|l|}{$\begin{array}{l}\text { Intensitas Pemanfaatan } \\
\text { Lahan }\end{array}$} \\
\hline KDB Maks & \multicolumn{2}{|c|}{$40 \%$} & \multicolumn{3}{|c|}{$60 \%$} & $80 \%$ \\
\hline KLB Maks & \multicolumn{2}{|r|}{2} & \multicolumn{3}{|c|}{2} & 2 \\
\hline \multicolumn{7}{|l|}{ Tata Masa Bangunan } \\
\hline Ketinggian Bangunan & \multicolumn{5}{|c|}{4 lantai atau $20 \mathrm{~m}$} & $\begin{array}{c}5 \text { lantai atau } 25 \\
\mathrm{~m}\end{array}$ \\
\hline GSB Muka & \multicolumn{6}{|c|}{$1 / 2$ rumija +1} \\
\hline \multicolumn{7}{|l|}{ Sistem Pergerakan } \\
\hline $\begin{array}{l}\text { Pergerakan Bermotor: } \\
\text { Lebar min. Jalan }\end{array}$ & \multicolumn{6}{|c|}{$7 \mathrm{~m}$} \\
\hline $\begin{array}{l}\text { Pergerakan Non motor: } \\
\text { Lebar min Jalur } \\
\text { pedestrian }\end{array}$ & $4 \mathrm{~m}$ & $5 \mathrm{~m}$ & $3 \mathrm{~m}$ & $3 \mathrm{~m}$ & $3 \mathrm{~m}$ & $2 \mathrm{~m}$ \\
\hline Parkir & \multicolumn{6}{|c|}{ Komunal } \\
\hline \multirow[b]{2}{*}{ Tata Kualitas bangunan } & \multicolumn{6}{|c|}{ Penerapan nilai Piil Pesenggiri padagubahan rancangan pada masing-masing segmen } \\
\hline & Juluk An & & $\begin{array}{l}\text { Nemui } \\
\text { Nyimah }\end{array}$ & Tittie Gumattie & $\begin{array}{l}\text { Ngah } \\
\text { Nyampur }\end{array}$ & Sakai Sambian \\
\hline
\end{tabular}

Penerapan smart corridor tidak hanya berkaitan dengan penggunaan teknologi saja, namun smart corridor juga berkaitan bagaimana pelayanan koridor yang ramah dan berkelanjutan (Orlowski dan Romanoska, 2018). Pada sistem pergerakan non-motor akan direncanakan ramah bagi pejalan kaki dan pesepeda. Jalur sepeda dan pejalan kaki akan diintegrasikan dengan ketentuan lebar minimal berkisar anatara 2- $4 \mathrm{~m}$, lebar ini akan berkaitan dengan tingkat layanan yang diinginkan dan ketersediaan jalur non bermotor yang ada (lihat Tabel 2).

Pengaturan kendaraan umum di Koridor Ryacudu akan diintegrasikan dengan pelayanan Smart Bus Rapid Transportation (Smart BRT) ITERA. Smart BRT ini nantinya tidak hanya melayani mahasiswa ITERA namun juga masyarakat umum. Pelayanan Smart BRT ITERA akan didukung dengan teknologi berbasis android maupun ios dimana pengguna bus nantinya dapat melihat posisi dari BRT secara realtime (Gambar 11 menunjukan titik halte Smart BRT ITERA). Hal ini merupakan bentuk penerapan smart corridor di Jalan Ryacudu.terdapat sembilan titik halte yang direncanakan, halte ini juga akan diintegrasikan dengan stasiun LRT. Sistem perparkiran yang akan direncanakan di koridor ini akan diarahkan pada sistem komunal dan tidak ada parkir on street. Hal ini ditujukan agar mengurangi hambatan sampingan yang disebabkan oleh sistem parkir on street. Komunal parkir direncanakan pada setiap blok perdagangan dan jasa.

Sistem ruang terbuka publik, RTH, akan mengadopsi konsep pengembangan infrastruktur hijau. Konsep infrastruktur hijau menekankan adanya keterhubungan antara area hijau (Hub) dengan Jalur hijau (link). Tekoneksinya area hijau oleh jalur hijau nantinya berdampak pada memaksimalkan manfaat RTH secara ekologis (Benedic and McMohan, 2001). Setiap segmen yang ada memiliki minimal satu RTH berbentuk area yang dihubungkan oleh jalur hijau jalan berupa median jalan dan jalurhijau di jalur pejalan kaki. 


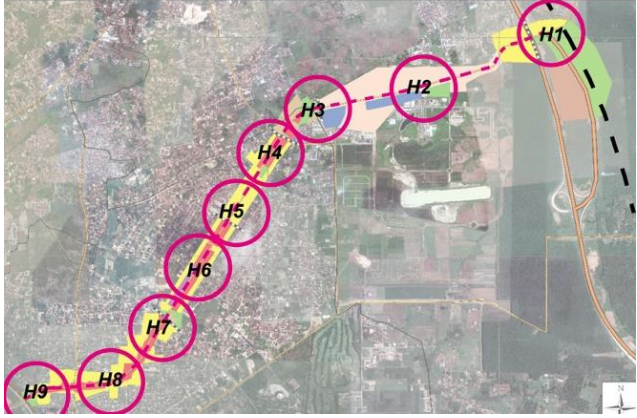

Gambar 11 Titik Halte Smart BRT ITERA

Penataan RTH yang berbentuk area difungsikan sebagai ruang terbuka publik yang dapat memaksimalkan manfaat sosial dan ekologis. Secara sosial, RTH menjadi ruang interaksi masyarakat dan Secara ekologis RTH diarahkan sebagai kawasan untuk menyerap polusi udara dan rekayasa iklim mikro.

\section{Kesimpulan}

Koridor Ryacudu merupakan salah satu kawasan yang terdampak akibat dari perkembangan kota Bandar Lampung sebagai Kota Metropolitan. Kawasan ini mengalami perubahan yang signifikan yang dipengaruhi oleh pembanguna infrastruktur dan sarana berskala nasional seperti JTTS dan Kawasan Pendidikan Terpadu LARALIN. Visi yang diusung untuk pengembangan kawasan Koridor Ryacudu dimasa yang akan datang adalah mewujudkan Koridor Ryacudu sebagai Smart Groth Corridor dengan menciptakan karakter kawasan yang bercorakan budaya lampung. Smart growth diwujudkan melalui penataan kawasan yang terkendali dan berbentuk kompak, smart corridor diintepretasikan dengan mengembangkan koridor yang ramah lingkungan dan penggunaan teknologi informasi dan komunikasi dalam pengelolaan sistem pergerakannya. Karakter lokal dihidupkan melalui pengadosian palsafah hidup masyarakat Lampung Piil Pesenggiri sebagai citra kawasan. Panduan rancangan kawasan ini belum terlalu operasional untuk penerapannya dimasa yang akan datang, oleh karenanya diperlukan penyusunan Detail engginering Design (DED) Koridor Ryacudu sehingga kualitas kawasan yang diinginkan dapat terwujud.

\section{DaftarPustaka}

Badan Pusat Statistik Kota Bandar Lampung. 2020.Kependudukan.https://bandarla mpungkota.bps.go.id/

Cliff M et al. 1999. Urban Design: Method and techniques. Oxford: Architectural Press

Dril N, Galkin A, dan Bibik N. 2016. Applying city marketing as a tool to support sustainable development in small city: case study in Ukraine. Prosiding 2nd international conference "green cities - green logistics for greener cities" $P$ 46-53

Klarin T. 2018. The Concept of Sustainable Development: from its begining to contemporary issue. Zegreb International Review of Economics and Business, Vol. 21 P 67-94. DOI: 10.2478/zireb-2018-0005

Lang J. 1994. Urban design: The American Experience. New York: Van Nostrand Reinhold.

Nurrohman T. 2017. Piil Pesenggiri: Problem Inferioritas dan Relevansi Kearifan Lokan dalam Konteks Kepemimpinan. IAIN Metro.

Orlowski A dan Romanoska P. 2018. Smart cities concept: smart mobility indicator, cybernetic and system, 50:2, 118-131, Doi:

10.1080/01969722.2019.1565120

Permen PU No. 06/PRT/M/20017 tentang Pedoman umum rencana tata bangunan dan lingkungan.

Pranoto $\mathrm{H}$, dan Wibowo A. 2018. Identifikasi Nilai Kearifan Lokal (local Wisdom) Piil Pesenggiri dan Perananya dalam Pelayanan Konseling Lintas Budaya. Jurnal Bimbingan Konseling Indonesia, Volume 3 No 2, P 36-42.

Shah MM. 2008. Sustainable Development. Encyclopedia of Ecology. P 34433446.

ScienceDirect: https://doi.org/10.1016/B978008045405-4.00633-9

Shirvani H. 1985. The Urban Design Process. New York: Van Nostrand Reinhold Company

Sinaga RM. 2012. (Re)produksi Piil Pesenggiri: identitas Etnis Lampung dalam Hubungan dengan Pendatang. Jurnal Antropologi Indonesia, Vol. 33, Universitas Indonesia. 
Undang-Undang Republik Indonesia No. 26

Tahun 2007 Tentang Penataan

Ruang.

UNDP. 2016. Sustainable Urbanization Strategy: UNDP's Suppoert to sustainable, inclusive, and resilient cities in the developing world.

Yunus, HS .2010. Metodologi Penelitian Wilayah Kontemporer. Pustaka Pelajar. Yogyakarta. 